\title{
Mice with RyR1 mutation (Y524S) undergo hypermetabolic response to simvastatin
}

\author{
Mark Knoblauch ${ }^{\dagger}$, Adan Dagnino-Acosta ${ }^{\dagger}$ and Susan L Hamilton ${ }^{*}$
}

\begin{abstract}
Background: Statins are widely used drugs for the treatment of hyperlipidemia. Though relatively safe, some individuals taking statins experience rhabdymyolysis, muscle pain, and cramping, a condition termed statin-induced myopathy (SIM). To determine if mutations in the skeletal muscle calcium $\left(\mathrm{Ca}^{2+}\right)$ release channel, ryanodine receptor type 1 (RyR1), enhance the sensitivity to SIM we tested the effects of simvastatin, the statin that produces the highest incidence of SIM in humans, in mice with a mutation (Y524S, 'YS') in RyR1. This mutation is associated with malignant hyperthermia in humans. Exposure of mice with the YS mutation to mild elevations in environmental temperature produces a life-threatening hypermetabolic response (HMR) that is characterized by increased oxygen consumption $\left(\mathrm{VO}_{2}\right)$, sustained muscle contractures, rhabdymyolysis, and elevated core body temperature.
\end{abstract}

Methods: We assessed the ability of simvastatin to induce a hypermetabolic response in the YS mice using indirect calorimetry and to alter $\mathrm{Ca}^{2+}$ release via RyR1 in isolated flexor digitorum brevis (FDB) fibers from WT and YS mice using fluorescent $\mathrm{Ca}^{2+}$ indicators. We also tested the ability of 5-aminoimidazole-4-carboxamide ribonucleoside (AICAR) to protect against the simvastatin effects.

Results: An acute dose of simvastatin triggers a hypermetabolic response in YS mice. In isolated YS muscle fibers, simvastatin triggers an increase in cytosolic $\mathrm{Ca}^{2+}$ levels by increasing $\mathrm{Ca}^{2+}$ leak from the sarcoplasmic reticulum (SR). With higher simvastatin doses, a similar cytosolic $\mathrm{Ca}^{2+}$ increase occurs in wild type (WT) muscle fibers. Pre-treatment of YS and WT mice with AICAR prevents the response to simvastatin.

Conclusions: A mutation in RyR1 associated with malignant hyperthermia increases susceptibility to an adverse response to simvastatin due to enhanced $\mathrm{Ca}^{2+}$ release from the sarcoplasmic reticulum, suggesting that RyR1 mutations may underlie enhanced susceptibility to statin-induced myopathies. Our data suggest that AICAR may be useful for treating statin myopathies.

Keywords: Statin-induced myopathy, Simvastatin, RyR1, Myopathy, Calcium signaling

\section{Background}

Statins (3-hydroxy-3-methylglutaryl coenzyme-A (HMGCoA) reductase inhibitors) are cholesterol-lowering drugs that have proven effective in decreasing low-density lipoprotein (LDL) levels and improving overall health [1]. For the majority of patients, statins are well tolerated with few side effects. However, up to $10 \%$ of patients on a statin regimen display muscle-related symptoms including soreness, fatigue, and an increase in circulating levels of musclespecific proteins (for example creatine kinase $(\mathrm{CK})$ ) that

\footnotetext{
* Correspondence: susanh@bcm.edu

${ }^{\dagger}$ Equal contributors

Department of Molecular Biology and Biophysics, Baylor College of Medicine, 1 Baylor Plaza, Houston, TX 77030, USA
}

results in a condition termed statin-induced myopathy (SIM) $[2,3]$. A mechanism to explain the underlying cause of SIM has yet to be elucidated.

One emerging theory of SIM has centered on statins' potential to modulate intramyofiber calcium $\left(\mathrm{Ca}^{2+}\right)$ homeostasis [4-6]. This theory stems in part from the finding that the direct application of simvastatin to healthy human myofibers triggers a significant increase in cytosolic $\mathrm{Ca}^{2+}$ [7]. The sudden release of $\mathrm{Ca}^{2+}$ in response to direct application of statins in vitro has been suggested to originate from both mitochondria and the sarcoplasmic reticulum (SR) $[5,8,9]$, the predominant $\mathrm{Ca}^{2+}$ storage organelle within the myofiber. The potential involvement of

\section{Biomed Central}


the SR in statin-induced $\mathrm{Ca}^{2+}$ release is particularly intriguing given the recent findings that mutations in ryanodine receptor type 1 (RyR1), the $\mathrm{Ca}^{2+}$ release channel of the SR, may underlie some instances of SIM $[10,11]$. Mutations in RyR1 are known to produce malignant hyperthermia $(\mathrm{MH})$, a life-threatening condition where uncontrolled release of $\mathrm{Ca}^{2+}$ within the myofiber is triggered by exposure to certain volatile inhalants, elevated temperature, or exercise [12,13]. This uncontrolled release of $\mathrm{Ca}^{2+}$ results in sustained muscle contractions, elevated core temperature, rhabdomyolysis and, if unabated, death [12].

At present our understanding of the link between RyR1 mutations and statin myopathies has been limited to in vitro work with muscle biopsies. Metterlein et al. found that biopsied muscle from $\mathrm{MH}$-sensitive swine exhibit contraction upon exposure to statins in vitro [10]. Similarly, Guis et al. found that muscle biopsies from seven of nine human subjects exhibiting the signs of SIM expressed abnormal in vitro contracture tests (IVCT) used to screen for susceptibility to $\mathrm{MH}$ [11].

These in vitro findings combined with evidence that simvastatin modifies $\mathrm{Ca}^{2+}$ homeostasis suggest that RyR1 mutations may underlie enhanced susceptibility to SIM. We developed a mouse model (Y524S, 'YS') with a RyR1 knock-in mutation of tyrosine 524 to serine [13], which in humans (Y522S) is associated with $\mathrm{MH}$ [13]. Mice homozygous for the mutation die at birth, while heterozygous YS mice exhibit a hypermetabolic response (HMR) to elevated $\left(37^{\circ} \mathrm{C}\right)$ temperature, volatile anesthetics, or exercise in a warm environment. These mice are a valuable tool for studying some RyR1-associated disorders. The purpose of the present study was to determine whether mice with this RyR1 mutation (Y524S) display HMR when given simvastatin and to evaluate the effects of simvastatin on intramyofiber $\mathrm{Ca}^{2+}$ homeostasis.

\section{Methods}

\section{Animal care and handling}

All procedures were approved by the Institutional Animal Care and Use Committee at Baylor College of Medicine, Houston, TX, USA. As previously described, male RyR1 ${ }^{\text {Y524S/WT }}$ ('YS') mice were developed and used in conjunction with wild type (WT) littermate controls at 8 to 10 weeks of age. Mice were maintained on a 12:12 light:dark cycle, had ad libitum access to water and standard mouse chow, and were limited to normal cage activity only. All mice were sacrificed at the same time of day, consisting of cervical dislocation after anesthetization under isoflurane.

\section{Statin preparation}

Simvastatin was purchased from the manufacturer (LKT Laboratories, St Paul, MN, USA) in powder form. For studies involving injection into mice for indirect calorimetry, simvastatin powder was dissolved in dimethyl sulfoxide (DMSO). For single-fiber perfusion work, a $12 \mathrm{mM}$ simvastatin stock was prepared in $10 \% \mathrm{EtOH}$ similar to previous studies [14]. After adjusting the $\mathrm{pH}$ to 7.0, the solution was brought up to $12 \mathrm{mM}$ concentration in Tyrode's solution containing $121 \mathrm{mM} \mathrm{NaCl}, 5 \mathrm{mM} \mathrm{KCl}$, $1.8 \mathrm{mM} \mathrm{CaCl} 2,500 \mu \mathrm{M} \mathrm{MgCl}, 400 \mu \mathrm{M} \mathrm{NaH}_{2} \mathrm{PO}_{4}, 100$ $\mu \mathrm{M}$ EDTA, $5.5 \mathrm{mM}$ glucose, and $24 \mathrm{mM} \mathrm{NaHCO}_{3}$. Separately, a vehicle-only stock was prepared identically but without the addition of simvastatin. These prepared stocks were aliquoted and frozen at $-80^{\circ} \mathrm{C}$ until use.

\section{Indirect calorimetry monitoring of $\mathrm{VO}_{2}$ max}

Those YS and WT mice used to determine the effects of statin dosing in vivo were removed from their cage, weighed, and injected IP with an 30-80 mg/ $/ \mathrm{kg}$ dose of either simvastatin dissolved in DMSO or DMSO alone ('vehicle'). The mice were then returned to their cages for 30 minutes, after which they were placed individually into an environmental chamber at $32^{\circ} \mathrm{C}$ containing indirect calorimetry chambers (Oxymax System, Columbus Instruments, Columbus, OH, USA), which allowed for monitoring of maximum oxygen consumption $\left(\mathrm{VO}_{2}\right.$ $\max (\mathrm{mL} / \mathrm{kg} / \mathrm{min}))$. Separately, to evaluate the effectiveness of a pharmaceutical agent shown previously to prevent heat-induced HMR response in YS mice [15], additional YS mice were injected IP with a $600 \mathrm{mg} / \mathrm{kg}$ dose of 5-aminoimadazole-4-carboxamide ribonucleoside (AICAR) 20 minutes after simvastatin injection.

\section{Fiber isolation}

For mice destined for single-fiber $\mathrm{Ca}^{2+}$ study, the flexor digitorum brevis (FDB) muscle was removed and immediately placed into Dulbecco's modified Eagle's medium (DMEM) containing $3 \mathrm{mg} / \mathrm{mL}$ collagenase and 10\% (v/v) fetal bovine serum. After a 2-hour incubation at $37^{\circ} \mathrm{C}$, whole FDB muscles were transferred to $1 \mathrm{~mL}$ of DMEM and plunged ten times through a $1 \mathrm{~mL}$ pipette tip to separate individual fibers. Next, $150 \mu \mathrm{L}$ of DMEM containing separated FDB fibers was placed onto a $25 \mathrm{~mm}$ glass coverslip that had been incubated for 2 hours with $20 \mu \mathrm{g} / \mathrm{mg}$ of laminin in PBS and then subjected to two washes in PBS and a final wash in DMEM. Prior to use, plated fibers were incubated overnight at $37^{\circ} \mathrm{C}$ in DMEM containing antibiotic-antimycotic (Gibco, Carlsbad, CA, USA).

\section{Isolated fiber preparation and imaging}

To assess the sensitivity to simvastatin, after the overnight incubation the fibers were next incubated for 1 hour at room temperature in either DMEM containing $(10 \mu \mathrm{M})$ Fura-2 acetoxymethyl ester (Fura-2 AM) or 30 minutes in DMEM containing $(5 \mu \mathrm{M})$ Mag-fluo-4, with 
$(20 \mu \mathrm{M})$ contraction-inhibitor 4-methyl-N-(phenylmethyl) benzenesulfonamide (BTS). Fibers were placed in a temperature controlled chamber (Dagan Corporation, Minneapolis, MN, USA) on the stage of an inverted epifluorescence microscope (Nikon Inc, Melville, NY, USA) and warmed to $32^{\circ} \mathrm{C}$ over a 5-minute period in Tyrode's solution. Fluorescence emission was captured using a high speed, digital QE CCD camera (TILL Photonics, Pleasanton, CA, USA). Each fiber was tested against a single dose of simvastatin, and peak fluorescence values were averaged across all fibers per group for each concentration.

\section{Simvastatin sensitivity and AICAR effectiveness in isolated fibers}

To determine the effects of simvastatin dosing, YS and WT fibers loaded with Fura-2 AM were perfused for 2 minutes in warmed $\left(32^{\circ} \mathrm{C}\right)$ Tyrode's solution for recording of baseline $\mathrm{Ca}^{2+}$ levels, followed by a 3-minute exposure at specified doses of simvastatin. Separately, isolated fibers used to test AICAR's effectiveness at preventing the statin-modulated change in $\mathrm{Ca}^{2+}$ were pre-incubated in $1 \mathrm{mM}$ AICAR in conjunction with the 1-hour incubation in DMEM/Fura-2 AM before exposure to $500 \mu \mathrm{M}$ and $1 \mathrm{mM}$ simvastatin in the YS and WT, respectively. Fura-2 fluorescence was recorded and converted to cytosolic $\mathrm{Ca}^{2+}$ values as previously reported [16].

4-CMC-induced $\mathrm{Ca}^{2+}$ store depletion in isolated fibers

To evaluate the effects of simvastatin on $\mathrm{SR} \mathrm{Ca}^{2+}$ store depletion, isolated fibers were exposed to 4-chloro-mcresol (4-CmC) immediately after 3 minutes of incubation in $500 \mu \mathrm{M}$ simvastatin. 4-CmC was applied to either YS or WT fibers at the dose found to induce maximal $\mathrm{Ca}^{2+}$ release without causing death of the individual fibers, which we determined to be $1 \mathrm{mM}$ in the YS and $2.5 \mathrm{mM}$ in the WT mice.

\section{Statistical analysis}

A Student's $t$-test was used for comparison between groups to test significance values of $P<0.05\left(^{*}\right), P<0.01$ $\left.{ }^{(* *)}\right)$, and $P<0.001{ }^{(* * *)}$. Dose-response curves were fit using 4-parameter (oxygen consumption $\left(\mathrm{VO}_{2}\right)$ ) or 3parameter (single-fiber dose-response) Hill function curves in SigmaPlot, version 12.0 (Systat Software, San Jose, CA, USA). YS data was additionally fitted with a biphasic function using GraphPad Prism, version 6 (GraphPad Software, La Jolla, CA, USA).

\section{Results}

\section{Simvastatin triggers HMR in YS mice}

We previously demonstrated that changes in $\mathrm{VO}_{2}$ could be used to detect the HMR response in the YS mice exposed to elevated environmental temperatures [15]. This approach allows early detection of the HMR and allows the mice to be euthanized prior to a full body contraction and death. To determine if statins also trigger an HMR response, we injected mice with an acute dose of simvastatin (IP 30 to $80 \mathrm{mg} / \mathrm{kg}$ ) and placed the mice in the chamber $\left(32^{\circ} \mathrm{C}\right.$, a thermoneutral temperature that does not trigger HMR in the untreated YS mice) of the indirect calorimeter and measured $\mathrm{VO}_{2}$ as a function of time after injection. All YS mice injected with 60 or $80 \mathrm{mg} / \mathrm{kg}$ simvastatin exhibited subsequent signs of $\mathrm{HMR}$, which included increased $\mathrm{VO}_{2}$ (Figure 1A), severe muscle contractures and increased heat production. After injection with simvastatin, a significantly higher peak $\mathrm{VO}_{2}$ occurred in YS mice receiving $60 \mathrm{mg} / \mathrm{kg}(P<0.05)$ and $80 \mathrm{mg} / \mathrm{kg}(P<0.001)$ doses when compared against YS mice injected with the vehicle. Figure $1 \mathrm{~B}$ shows the dose-response curve for peak $\mathrm{VO}_{2}$ as a function of simvastatin dose in the YS mice.

To determine if the statin-induced HMR event was similar to heat-induced HMR in the YS mice, we injected the YS mice with $80 \mathrm{mg} / \mathrm{kg}$ of simvastatin followed by $600 \mathrm{mg} / \mathrm{kg}$ of AICAR, which we have previously shown to prevent temperature-induced HMR in the YS mice by decreasing $\mathrm{Ca}^{2+}$ leak from RyR1 [15]. AICAR eliminated the statin-associated HMR in YS mice by preventing the significant $(P<0.01)$ increase in $\mathrm{VO}_{2}$ that occurs in YS mice not receiving the AICAR treatment (Figure $1 \mathrm{C}$ ).

\section{Myofibrillar $\mathrm{Ca}^{2+}$ leak is more sensitive to simvastatin in YS compared to WT muscle fibers}

The strong protective effect of AICAR on the simvastatin response of the YS mice suggests that statininduced HMR in these mice is likely due to altered $\mathrm{Ca}^{2+}$ handling within the myofiber. We tested the effects of simvastatin in isolated FDB fibers of YS and WT mice using the fluorescent dye Fura- 2 to assess changes in cytosolic $\mathrm{Ca}^{2+}$ concentrations. We found that simvastatin triggered higher cytosolic $\mathrm{Ca}^{2+}$ levels in YS fibers at lower concentrations $(500 \mu \mathrm{M}(P<0.001)$ and $750 \mu \mathrm{M}$ $(P<0.01))$ than in WT FDB fibers (Figure 2). As previously shown with human fibers [7], WT fibers displayed increased $\mathrm{Ca}^{2+}$ in response to higher doses of simvastatin $(1.5 \mathrm{mM}(P<0.01))$. The concentration response curves in the YS and WT mice were best fit using a Hill function (3-parameter) with a resulting $\mathrm{EC}_{50}$ of $0.6 \mathrm{mM}$ in the YS and $0.9 \mathrm{mM}$ in the WT mice. Since the YS fibers are from heterozygous mice, the $\mathrm{Ca}^{2+}$ response reflects the heterogeneous response from a mixture of mutant channels (in various combinations of mutation and WT subunits) and WT channels. Using a 2-site model, we obtain $\mathrm{EC}_{50} \mathrm{~s}$ of 0.4 and $0.9 \mathrm{mM}$. $\mathrm{Ca}^{2+}$ concentrations were calculated from the Fura-2 fluorescence as described in Methods. 

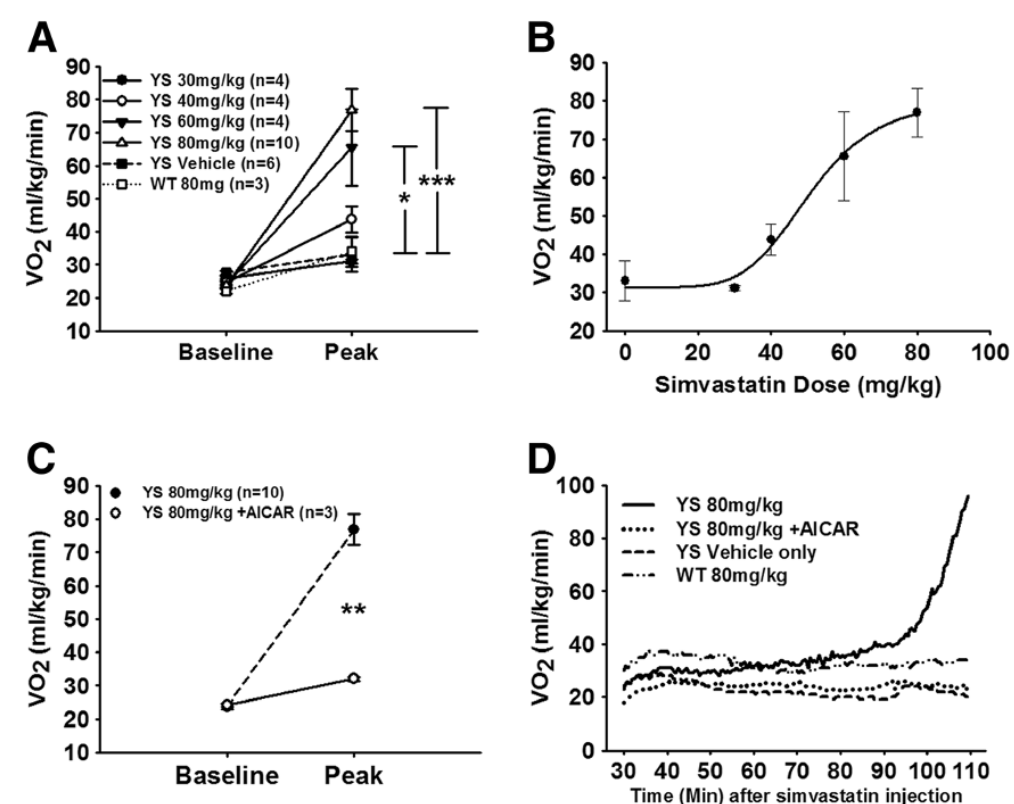

Figure 1 An acute dose of simvastatin at $32^{\circ} \mathrm{C}$ results in higher peak $\mathrm{VO}_{2}$ levels in $\mathrm{YS}$ compared to WT mice. (A) IP injection of simvastatin triggers significantly higher peak $\mathrm{VO}_{2}$ values at $60 \mathrm{mg} / \mathrm{kg}(P<0.05)$ and $80 \mathrm{mg} / \mathrm{kg}(P<0.001)$ compared to vehicle-only injection. (B) Curve-fit of increasing simvastatin doses in YS mice. (C) Pre-treatment with $600 \mathrm{mg} / \mathrm{kg}$ AICAR results in significantly $(P<0.01)$ lower peak VO 2 values when administered 20 minutes after simvastatin treatment in YS mice. (D) Representative $\mathrm{VO}_{2}$ tracings of YS mice receiving $80 \mathrm{mg} / \mathrm{kg}$ of simvastatin show increasingly higher $\mathrm{VO}_{2}$ values than $\mathrm{YS}$ mice treated with both $80 \mathrm{mg} / \mathrm{kg}$ simvastatin and $600 \mathrm{mg} / \mathrm{kg}$ AICAR, vehicle-only (DMSO), or WT mice treated with 80 mg/kg simvastatin. AICAR, 5-aminoimidazole-4-carboxamide ribonucleoside; DMSO, dimethyl sulfoxide; $\mathrm{VO}_{2}$, oxygen consumption; $\mathrm{WT}$, wild type; YS, Y524S.

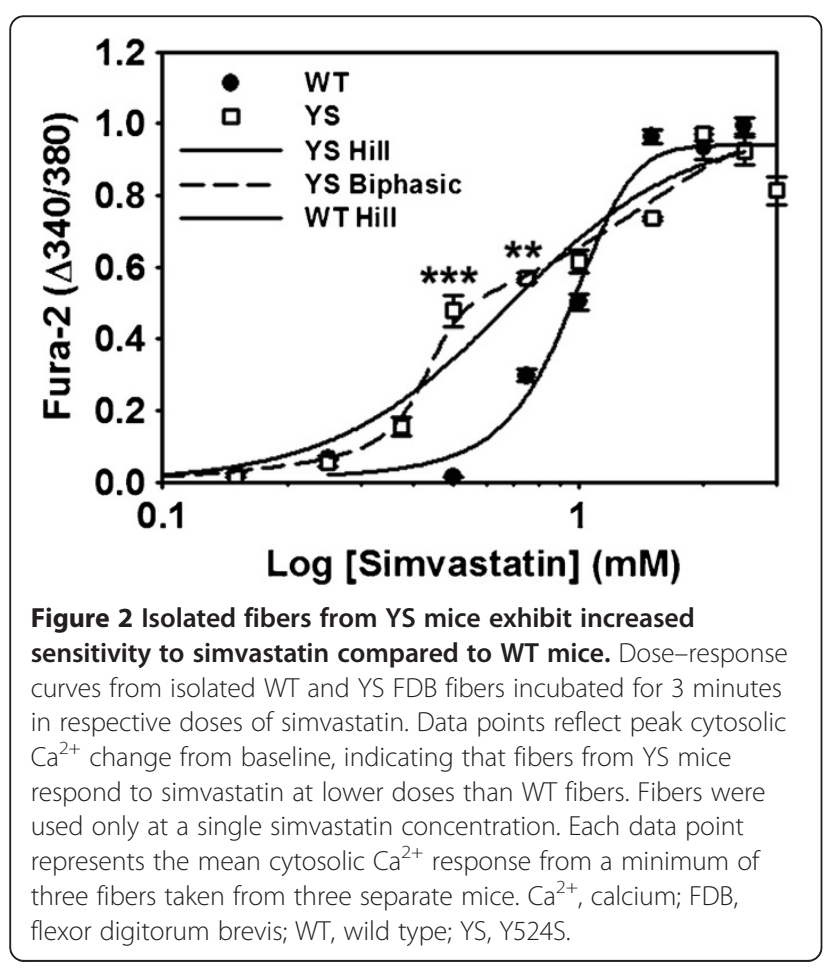

Simvastatin depletes SR $\mathrm{Ca}^{2+}$ stores in FDB fibers isolated from YS mice

$\mathrm{Ca}^{2+}$ stores in YS FDB fibers are decreased by exposure to elevated temperatures [17]. To determine if a reduction in $\mathrm{Ca}^{2+}$ stores occurs with simvastatin, we used Mag-fluo-4, a low-affinity $\mathrm{Ca}^{2+}$ indicator, and $4-\mathrm{CmC}$ to assess the readily releasable $\mathrm{SR} \mathrm{Ca}^{2+}$ stores [18]. 4-CmC was applied to isolated fibers immediately after a 3minute incubation with simvastatin. We found a significant $(P<0.05)$ decrease in the readily releasable $\mathrm{Ca}^{2+}$ stores in YS fibers exposed to $500 \mu \mathrm{M}$ simvastatin compared with YS fibers exposed to vehicle-only (Figure 3), while no difference was found in WT fibers at this concentration of simvastatin. This finding suggests that the increased cytosolic $\mathrm{Ca}^{2+}$ levels in the YS mice that occur after exposure to simvastatin are due to $\mathrm{SR} \mathrm{Ca}^{2+}$ leak leading to $\mathrm{SR} \mathrm{Ca}^{2+}$ store depletion.

We assessed the ability of AICAR to regulate the simvastatin-induced increase in $\mathrm{Ca}^{2+}$ leak in the YS fibers. Isolated YS fibers were incubated with $1 \mathrm{mM}$ AICAR prior to incubation with $500 \mu \mathrm{M}$ simvastatin. As shown in Figure $4 \mathrm{~A}, \mathrm{Ca}^{2+}$ stores were protected from the simvastatin-induced depletion by prior administration of AICAR $(P<0.01)$. We determined if AICAR could also prevent the simvastatin-induced $\mathrm{Ca}^{2+}$ release at higher simvastatin doses in WT mice (Figure 4B). 


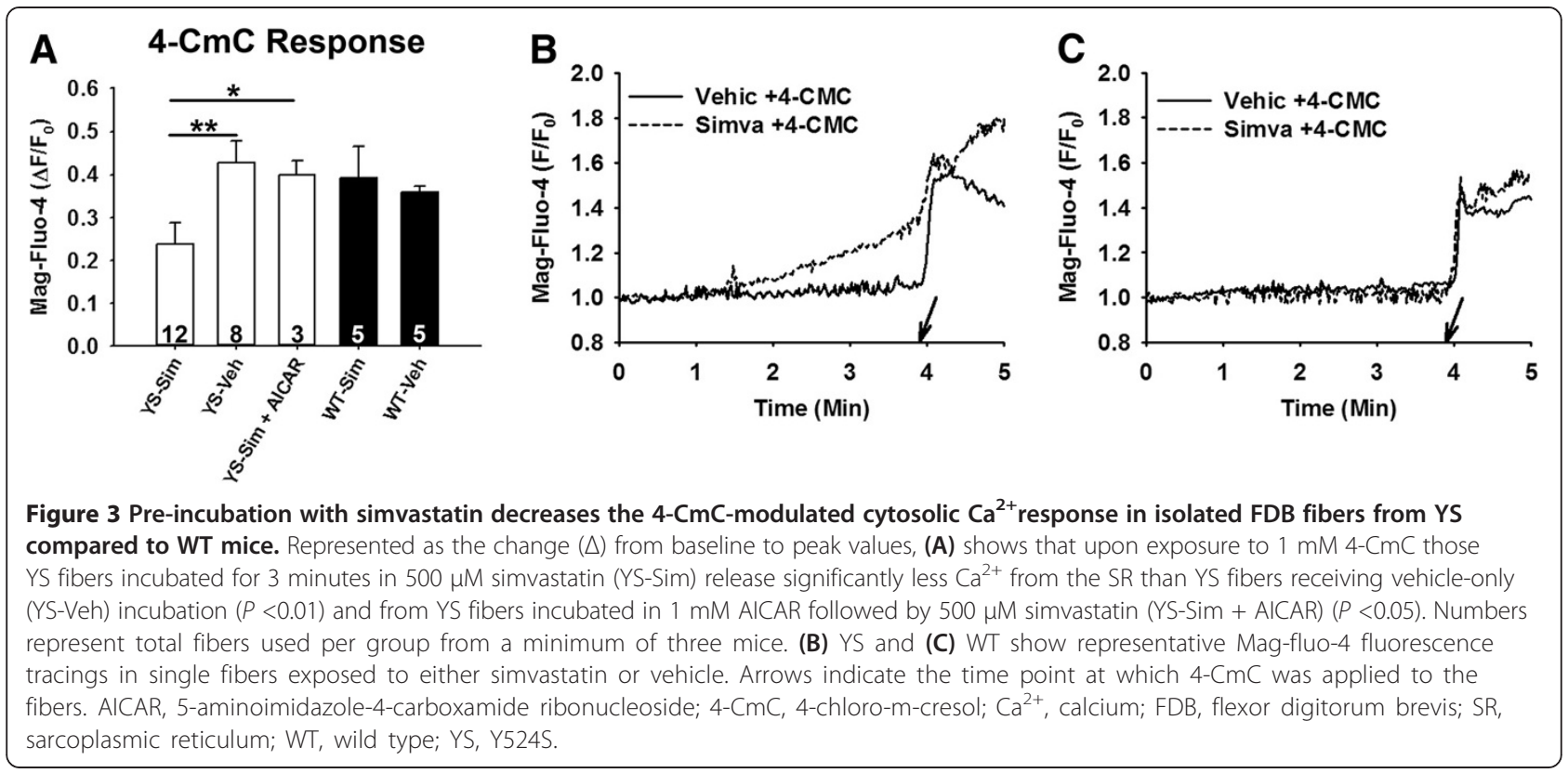

When WT fibers were incubated with $1 \mathrm{mM}$ simvastatin, we found that AICAR pre-treatment also greatly decreased $\mathrm{Ca}^{2+}$ release in WT fibers $(P<0.001)$, suggesting that statins have the potential to trigger $\mathrm{Ca}^{2+}$ release in normal fibers but require higher simvastatin concentrations than YS fibers and that AICAR may be a useful intervention for SIM even in patients without RyR1 mutations.

\section{Discussion}

Despite the prevalence of statin myopathies, a mechanism to explain the underlying trigger has remained elusive. The current study's objective was to determine whether a MH-associated defect in RyR1 increased sensitivity to simvastatin and whether AICAR, which prevents heat-induced HMR in the YS mice, blocked the response to simvastatin. We show that the YS mice
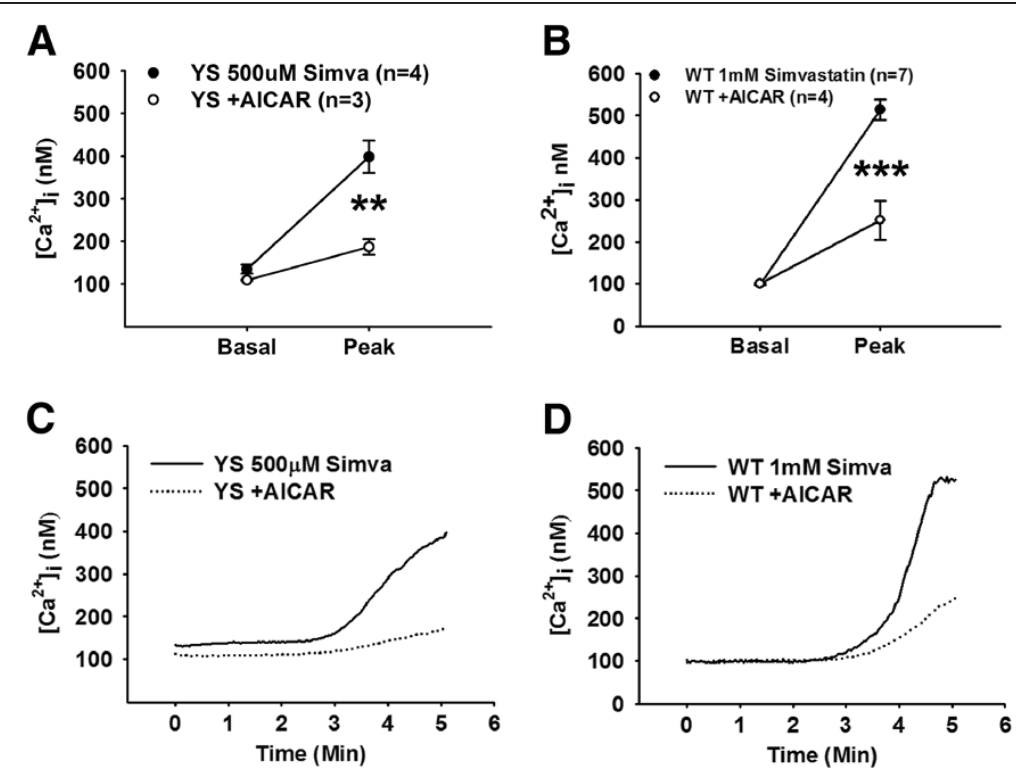

Figure 4 Pre-treatment with AICAR reduces the cytosolic $\mathrm{Ca}^{2+}$ response to simvastatin. Pre-incubation with $\mathrm{AlCAR}^{2}$ prevents $\mathrm{Ca}^{2+}$ release in (A) YS fibers exposed to $500 \mu \mathrm{M}$ simvastatin $(P<0.01)$ and in (B) WT fibers exposed to $1 \mathrm{mM}$ simvastatin $(P<0.001)$. (C) YS and (D) WT show change in $\mathrm{Ca}^{2+}$ concentration for AICAR-treated (dashed) and untreated (solid) fibers after exposure to either 500 HM (YS) or 1 mM (WT) simvastatin at 2 minutes. AICAR, 5-aminoimidazole-4-carboxamide ribonucleoside; Ca ${ }^{2+}$, calcium; WT, wild type; YS, Y524S. 
display an $\mathrm{MH}$-like response (elevated $\mathrm{VO}_{2}$, sustained muscle contractures, elevated body temperature) to an acute dose of simvastatin, and the degree of response is dose-dependent. Simvastatin also enhances SR $\mathrm{Ca}^{2+}$ leak and $\mathrm{SR} \mathrm{Ca}^{2+}$ store depletion in FDB fibers from both YS and WT mice but the response in WT mice requires higher concentrations of simvastatin. In FDB fibers from both YS and WT mice, the response to simvastatin was prevented by AICAR, suggesting that even in WT fibers the effect of simvastatin involves RyR1.

AICAR is a known activator of the energy sensing kinase, AMP-activated protein kinase (AMPK). We recently demonstrated, however, that AICAR also has a direct effect on RyR1 and rescues the YS mice from heat-induced sudden death independent of AMPK activation [15]. We now demonstrate that treatment of YS mice with AICAR, which decreases $\mathrm{Ca}^{2+}$ leak in the presence of cellular levels of ATP [15], prevents the simvastatin-associated increases in $\mathrm{VO}_{2}$ and heat production as well as greatly attenuates $\mathrm{Ca}^{2+}$ leak from the SR upon exposure of FDB fibers to simvastatin. AICAR also largely eliminates the statininduced $\mathrm{Ca}^{2+}$ release in healthy WT mice. These results suggest that AICAR might also be a potential therapeutic intervention to prevent statin myopathies associated with RyR1 mutations in sensitive individuals and protect against myopathies arising from high statin doses in individuals without RyR1 mutations.

\section{YS mutation explains clinical symptoms of SIM}

Alterations in $\mathrm{Ca}^{2+}$ signaling with simvastatin could explain many of the symptoms associated with SIM in humans including muscle fatigue, cramping, and increased levels of circulating CK. Depletion of stores contributes to fatigue, while increased resting $\mathrm{Ca}^{2+}$ is known to trigger $\mathrm{Ca}^{2+}$ release and muscle contraction, giving rise to muscle cramping similar to that which occurs in Brody disease. Brody disease results from a reduction in the number and activity of sarco/endoplasmic reticulum $\mathrm{Ca}^{2+}$-ATPase (SERCA) proteins in skeletal muscle, which inhibits the re-uptake of cytosolic $\mathrm{Ca}^{2+}$ during muscle activity $[19,20]$. Individuals afflicted with Brody disease complain of fatigue as well as muscle cramping that is exacerbated during periods of increased activity such as exercise [19]. These symptoms reflect those commonly reported among individuals experiencing SIM. Separately, elevated circulating CK levels among individuals experiencing SIM can also be explained by rhabdomyolysis triggered by the statin-modulated increase in cytosolic $\mathrm{Ca}^{2+}$ levels and activation of calpains [21,22]. Elevated CK levels are commonly experienced by individuals experiencing SIM.

\section{Clinical relevance}

An acute dose of simvastatin increases cytosolic $\mathrm{Ca}^{2+}$ levels within the myofiber and this increase occurs at lower simvastatin concentrations in the presence of a RyR1 mutation associated with $\mathrm{MH}$ in humans. The prevalence of genetic abnormalities capable of causing $\mathrm{MH}$ has been estimated to be as low as 1:3,000 [12]. Whereas the incidence of SIM is relatively low (approximately 10\%) among the millions of statin users, it is highly possible that those individuals exhibiting signs and symptoms of SIM are harboring an underlying RyR1 myopathy. Guis et al. showed that seven of nine individuals exhibiting symptoms of severe statin myopathy were found to have a positive IVCT, indicative of an underlying RyR1 abnormality [11]. Therefore, further research is needed to determine whether individuals experiencing SIM also have mutations in RyR1. If true, drugs such as AICAR that modulate RyR1 activity can be investigated as a potential therapy for these individuals, which may allow continued statin use without the side effects associated with SIM.

\section{Conclusions}

The YS mutation in RyR1 increases the sensitivity to the cholesterol-lowering medication simvastatin. This sensitivity is marked by systemic increases in $\mathrm{VO}_{2}$, muscle contractures and heat production due to a temporal release of $\mathrm{Ca}^{2+}$ into the cytosol from the SR. Pharmaceutical interventions that decrease $\mathrm{Ca}^{2+}$ leak from RyR1 (such as AICAR) prevent both the systemic manifestation of SIM and the statin-induced $\mathrm{Ca}^{2+}$ release from the SR in single fibers. We show that RyR1 mutation increases sensitivity to SIM, suggesting that individuals affected by SIM could harbor underlying RyR1 mutations and that AICAR may be an effective therapeutic intervention.

\section{Abbreviations}

4-CmC: 4-chloro-m-cresol; AICAR: 5-aminoimidazole-4-carboxamide ribonucleoside; AMPK: AMP-activated protein kinase; BTS: 4-methyl-N(phenylmethyl)benzenesulfonamide; $\mathrm{Ca}^{2+}$ : Calcium; CK: Creatine kinase; DMEM: Dulbecco's modified Eagle's medium; DMSO: Dimethyl sulfoxide; $\mathrm{EC}_{50}$ : Half maximal effective concentration; EDTA: Ethylenediaminetetraacetic acid; EtOH: Ethanol; FDB: flexor digitorum brevis; Fura-2 AM: Fura-2 acetoxymethyl ester; HMG-CoA: 3-hydroxy-3-methylglutaryl coenzyme-A; HMR: Hypermetabolic response; IP: Intraperitoneal; IVCT: In vitro contracture test; LDL: Low-density lipoprotein; MH: Malignant hyperthermia; RyR1: Ryanodine receptor type 1; SERCA: Sarco/endoplasmic reticulum $\mathrm{Ca}^{2+}$ ATPase; SIM: Statin-induced myopathy; SR: Sarcoplasmic reticulum; $\mathrm{VO}_{2}$ : Oxygen consumption; $\mathrm{VO}_{2}$ max: Maximum oxygen consumption; WT: Wild type; YS: Y524S

\section{Competing interests}

The authors declare that they have no competing interests.

\section{Authors' contributions}

MK conceived and developed the study, conducted indirect calorimetry experiments, assisted with $\mathrm{Ca}^{2+}$ imaging experiments, performed statistical analyses, and prepared the draft manuscript. ADA conducted $\mathrm{Ca}^{2+}$ imaging experiments, assisted with analyses, prepared data, and assisted with manuscript preparation. SLH created and maintained the YS mouse line, assisted with study design and data interpretation, and assisted with manuscript preparation. All authors read and approved the final manuscript. 


\section{Acknowledgements}

This was supported by NIH grants 5R01AR041802 and 5R01AR053349 to SLH. A.D.A. was supported by a postdoctoral fellowship from the Mexican Council of Science and Technology (186607). We would like to thank the Mouse Phenotyping Core at Baylor College of Medicine, Houston, TX, USA, for the use and assistance with the Oxymax indirect calorimetry system.

Received: 9 April 2013 Accepted: 9 August 2013

Published: 3 September 2013

\section{References}

1. Joy T, Hegele R: Narrative review: statin-related myopathy. Ann Intern Med 2009, 150(12):858-868.

2. Sathasivam S, Lecky B: Statin induced myopathy. BMJ 2008, 337:1159-1162.

3. Venero C, Thompson P: Managing statin myopathy. Endocrinol Metab Clin North Am 2009, 38(1):121-136.

4. Ghatak A, Faheem O, Thompson PD: The genetics of statin-induced myopathy. Atherosclerosis 2010, 210(2):337-343.

5. Sirvent P, Fabre O, Bordenave S, Hillaire-Buys D, Raynaud De Mauverger E, Lacampagne A, Mercier J: Muscle mitochondrial metabolism and calcium signaling impairment in patients treated with statins. Toxicol Appl Pharmacol 2012, 259(2):263-268.

6. Sirvent $P$, Mercier J, Lacampagne A: New insights into mechanisms of statin-associated myotoxicity. Curr Opin Pharmacol 2008, 8(3):333-338.

7. Sirvent P, Bordenave S, Vermaelen M, Roels B, Vassort G, Mercier J, Raynaud E, Lacampagne A: Simvastatin induces impairment in skeletal muscle while heart is protected. Biochem Biophys Res Commun 2005, 338(3):1426-1434.

8. Sirvent P, Mercier J, Vassort G, Lacampagne A: Simvastatin triggers mitochondria-induced $\mathrm{Ca} 2+$ signaling alteration in skeletal muscle. Biochem Biophys Res Commun 2005, 329(3):1067-1075.

9. Inoue R, Tanabe M, Kono K, Maruyama K, Ikemoto T, Endo M: Ca2+-releasing effect of cerivastatin on the sarcoplasmic reticulum of mouse and rat skeletal muscle fibers. J Pharmacol Sci 2003, 93(3):279-288.

10. Metterlein T, Schuster F, Tadda L, Hager M, Roewer N, Anetseder M: Statins alter intracellular calcium homeostasis in malignant hyperthermia susceptible individuals. Cardiovasc Ther 2010, 28(6):356-360.

11. Guis S, Figarella-Branger D, Mattei JP, Nicoli F, Le Fur Y, Kozak-Ribbens G, Pellissier JF, Cozzone PJ, Amabile N, Bendahan D: In vivo and in vitro characterization of skeletal muscle metabolism in patients with statininduced adverse effects. Arthritis Rheum 2006, 55(4):551-557.

12. Rosenberg H, Davis M, James D, Pollock N, Stowell K: Malignant hyperthermia. Orphanet J Rare Dis 2007, 2:21.

13. Chelu M, Goonasekera S, Durham W, Tang W, Lueck J, Riehl J, Pessah I, Zhang P, Bhattacharjee M, Dirksen R, Hamilton SL: Heat- and anesthesiainduced malignant hyperthermia in an RyR1 knock-in mouse. FASEB J 2006, 20:329-330

14. Leung B, Sattar N, Crilly A, Prach M, McCarey D, Payne H, Madhok R, Campbell C, Gracie J, Liew F, McInnes I: A novel anti-inflammatory role for simvastatin in inflammatory arthritis. J Immunol 2003, 170:1524-1530.

15. Lanner JT, Georgiou DK, Dagnino-Acosta A, Ainbinder A, Cheng Q, Joshi AD, Chen Z, Yarotskyy V, Oakes JM, Lee CS, Monroe TO, Santillan A, Dong K, Goodyear L, Ismailov II, Rodney GG, Dirksen RT, Hamilton SL: AICAR prevents heat-induced sudden death in RyR1 mutant mice independent of AMPK activation. Nat Med 2012, 18(2):244-251.

16. Dagnino-Acosta A, Guerrero-Hernández A: Variable luminal sarcoplasmic reticulum $\mathrm{Ca}^{2+}$ buffer capacity in smooth muscle cells. Cell Calcium 2009, 46:188-196.

17. Durham W, Aracena-Parks P, Long C, Rossi A, Goonasekera S, Boncompagni S, Galvan D, Gilman C, Baker M, Shirokova N, Protasi F, Dirksen R, Hamilton S: RyR1 S-nitrosylation underlies environmental heat stroke and sudden death in Y522S RyR1 knockin mice. Cell 2008, 133:53-65.

18. Herrmann-Frank A, Richter M, Lehmann-Horn F: 4-Chloro-m-cresol: a specific tool to distinguish between malignant hyperthermia-susceptible and normal muscle. Biochem Pharmacol 1996, 52:149-155.

19. Vattemi G, Gualandi F, Oosterhof A, Marini M, Tonin P, Rimessi P, Neri M, Guglielmi V, Russignan A, Poli C, van Kuppevelt T, Ferlini A, Tomelleri G: Brody disease: insights into biochemical features of SERCA1 and identification of a novel mutation. J Neuropathol Exp Neurol 2010, 69(3):246-252.

20. Voermans N, Laan A, Oosterhof A, van Kuppevelt T, Drost G, Lammens M, Kamsteeg E, Scotton C, Gualandi F, Guglielmi V, van den Heuvel L, Vattemi
G, van Engelen B: Brody syndrome: a clinically heterogeneous entity distinct from Brody disease: a review of literature and a cross-sectional clinical study in 17 patients. Neuromuscul Disord 2012, 22:944-954.

21. Belcastro A, Shewchuk L, Raj D: Exercise-induced muscle injury: a calpain hypothesis. Mol Cell Biochem 1998, 179(1-2):135-145.

22. Raastad T, Owe S, Paulsen G, Enns D, Overgaard K, Crameri R, Kiil S, Belcastro A, Bergersen L, Hallén J: Changes in calpain activity, muscle structure, and function after eccentric exercise. Med Sci Sports Exerc 2010, 42(1):86-95.

doi:10.1186/2044-5040-3-22

Cite this article as: Knoblauch et al:: Mice with RyR1 mutation (Y524S) undergo hypermetabolic response to simvastatin. Skeletal Muscle 2013 3:22.

\section{Submit your next manuscript to BioMed Central and take full advantage of:}

- Convenient online submission

- Thorough peer review

- No space constraints or color figure charges

- Immediate publication on acceptance

- Inclusion in PubMed, CAS, Scopus and Google Scholar

- Research which is freely available for redistribution

Submit your manuscript at www.biomedcentral.com/submit
C Biomed Central 